\title{
Research on Technological Innovation Talents of the Six Provinces of Mid-China based on BP Artificial Neural Networks of the Golden Section Theory
}

\author{
Huaping Zhang \\ Management \& Economics School of North China University of Water Resources and \\ Electric Power \\ zhanghuaping@ncwu.edu.cn
}

\begin{abstract}
Technological innovation talent is the core element of economic and social development. It is a symbol of a country's soft power reflected from the perspective of knowledge. Therefore it is theoretically valuable and practically significant for a country to evaluate the comprehensive level technological innovation. Based on the construction of evaluation index system of the technological innovation talents' competitiveness, we will use BP neural network to evaluate in this paper. We determine the actual situation of the evaluation system according to the input layer, hidden layer and output layer of the model as well as the number of neurons in each layer. The number of neurons in the input layer is the number of indices of technological innovation talents evaluation. The output layer represents the comprehensive ability level and has only one neuron. However, it is difficult to figure out the number of hidden layers of BP neural networks. We use the golden section method to accurately select their layers. This can effectively avoid the problem of excessive training error due to the random selection of hidden layer. Then we illustrate the accuracy and usefulness of this algorithm with the case of the technological innovation talents of the six central provinces. Tests show that the comprehensive ability of technological innovation talents of Hubei is the most powerful in the six central provinces and is followed by Anhui. The remaining four provinces have similar levels. The actual development of technological innovation talents agree well with the experimental results.
\end{abstract}

Keywords: innovative talents, Evaluation model, The BP neural network, The Golden Section method

\section{Introduction}

Innovative is the era feature of the 21 st century. In the 21 st century, both economic development and social progress are increasingly dependent on knowledge and technological innovation. After all, international competition is the talent competition and a competition of national innovation capabilities. Talent is the most critical in promoting knowledge innovation, technological innovation and improving the national innovation capacity. Those with creative talents have become the focus of attention. Talent especially the innovative talent is the key factor to build an innovative country. Without a grand innovation team to support, it is impossible to achieve the goal of building an innovative country. The worldwide competition of comprehensive national strength is ultimately a competition of talent especially innovative talent. One able to develop, attract and take good advantage of talent especially creative talents can grab the first resource to control strategic initiative and achieve development goals in the fierce international competition. 
Research on human capital theory has been and receiving increasing attention from scholars, experts of many countries in the world. Although there is commonly no special research on the competitiveness of the regional technological innovation competition abroad, there are plenty of studies scattered in a number of other related studies such as how to attract and develop talents based on the analysis of economic disparities in the region [1-3]; talent identification and classification [4]; Jeon D et al. pointed out that to some extent the potential of the personnel is influenced by the environment and has a huge effect on environment from the perspectives of environment and the potential of the personnel 5-7]; based on the interaction between creativity, cohesion of the talent and regional development, Hung $\mathrm{S}$ believed that human creativity and cohesion played an important role in the regional economic development [8-10]; Gardner TG pointed out that developing some talents conforming to the regional development can enhance the creativity and the developing power [11-12] ; some scholars studied in terms of talent mobility characteristics, causes and impact on the region [13-14]; Evi Hartmann believed that talent flow between different countries and regions can improve the competitiveness of the region; under the conditions of globalization, Harvey $\mathrm{M}$ and some other scholars researched on talent evaluation in terms of their performance, noted for innovative talents has a huge role in the regional economic development [15-16].

Based on the construction of the evaluation index system of technological innovation talent competitiveness, we use BP neural network to evaluate. We determine the input layer, hidden layer and output layer of the model as well as the number of neurons in each layer according to the actual situation of the evaluation system. The number of neurons in the input layer is the number of coordinated development evaluation indices. The output layer is the effect of joint development and has one neuron. The selection of the number of neurons in hidden layer is a very complex issue. In this paper, we will figure out the most appropriate number of hidden layers according to the golden theory. Then we illustrate the accuracy and usefulness of this algorithm technological innovation with the case of the six central provinces. Tests showed that the comprehensive capacity of technological innovation of Hubei is the strongest in the six central provinces, followed by Anhui and the remaining four provinces are of similar level. The layout of the article is as follows: in section two, we briefly introduce the basic model of BP neural network; section three describes the key components of our neural network; in section four we establish evaluation model and use the golden section method to improve BP network. At last we give the test results and conclusions through the strength of the six central provinces.

\section{BP Network Optimization Model}

BP neural network is a kind of feed forward networks and it consists of one input layer, some hidden layers and one output layer. Three-layer BP neural network is shown as figure 1. The number of input layer, hidden layer and output layer is respectively $\mathrm{n}, \mathrm{q}$ and $\mathrm{m}$. So the three-layer network can be displayed as $B P(n, q, m)$. It can be used to realize nonlinear mapping from $\mathrm{n}$-dimensional input vector $X^{n}=\left(X_{1}, X_{2}, \cdots, X_{n}\right)^{T}$ to $\mathrm{m}$-dimensional output vector $Y^{n}=\left(Y_{1}, Y_{2}, \cdots, Y_{m}\right)^{T}$. The number of input layers and output layers $\mathrm{n}$ and $\mathrm{m}$ can be ascertained according to specific issues. We have not got a mature method to ensure the value of q. Usually we set different values for q and select from them according to training result.

After ensuring the structure of $B P(n, q, m)$, the network parameters contain the weight of $\mathrm{i}$-th unit of input layer to $\mathrm{j}$-th unit of hidden layer $w_{i j}^{t}(i=1,2, \cdots, n ; j=1,2, \cdots, q)$, the weight of $\mathrm{j}$ th unit of hidden layer to k-th unit of output layer $w_{j k}^{\prime \prime}(j=1,2, \cdots, q ; k=1,2, \cdots, m)$, the activation threshold of $\mathrm{j}$-th unit of hidden layer $\theta_{j}^{H}(j=1,2, \cdots, q)$ as well as the activation threshold of kth unit of output layer $\theta_{k}^{o}(k=1,2, \cdots, m)$. All the weights and activation thresholds are generated randomly before network training. Suppose that we have P training samples in total, the $\mathrm{p}$-th 
$p(p=1,2, \cdots, P)$ training sample we input is transmitted forwards to hidden units first, under the effect of activation function we can get the output information of hidden layers.

$$
H_{p}=f\left(\sum_{i=1}^{n} W_{i j}^{t} X_{i p}-\theta_{j}^{H}\right)
$$

$j=1,2, \cdots, q ; p=1,2, \cdots, P$

Generally we use the Sigmoid type in activation function $f(u)$ :

$$
f(u)=\frac{1}{1+e^{-u}}
$$

The input information is transmitted to output layers and we can get the result as following:

$$
Y_{k p}=f\left(\sum_{j=1}^{q} W_{j k}^{o} H_{p}-\theta_{k}^{o}\right)
$$

$k=1,2, \cdots, m ; p=1,2, \cdots, P$

The above process is the information dissemination process forward of the network learning, the other procedure is the process of error counter propagation. If error exists between the network output and the desired output, then the error propagates backward. Use the formula (4) to adjust the network weights and thresholds:

$$
\Delta W(t+1)=\eta \frac{\partial E}{\partial W}+\alpha \Delta W(t)
$$

$\Delta \mathrm{W}(\mathrm{t})$ above represents corrections of weights and thresholds of t training sessions. $\eta$ and $\alpha$ represent proportional coefficient and momentum coefficient. $\mathrm{E}$ is error sum of square.

$$
E=\frac{1}{2} \sum_{k=1}^{m} \sum_{p=1}^{P}\left(Y_{p}-t_{p}\right)^{2}
$$

Repeat the two processes above until the error between network output and expected output can meet some certain requirements.

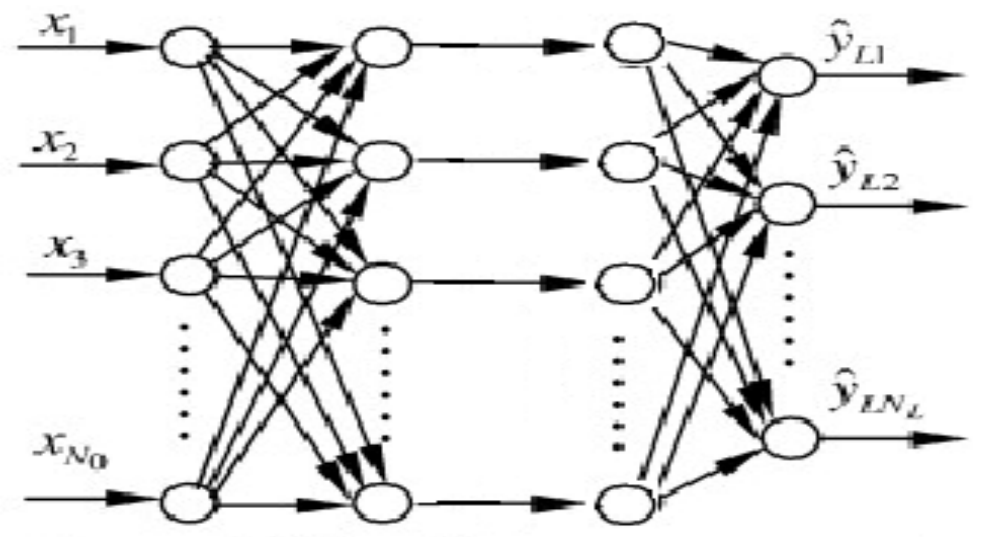

\section{Input Layer Hidden Layer Output Layer}

Figure 1. Structure of Three-layer Neural Network

\section{Activation Function of BP Network}

According to the formula (2) in the previous section, we can get that neural networks have a lot of activation functions. The excitation function is one of the main factors that determine the performance of neural network. If the excitation function of neuron is different, it will 
make the neurons with different mathematical models, which have different characteristics of information processing. Therefore, the correct selection of excitation function has important significance. There are many kinds of excitation function for the optimization model. Excitation function including threshold transform function, nonlinear transformation function and linear transformation function.

The concrete expressions are as follows:

(1) Threshold transform function

$$
f(x)= \begin{cases}1 & , x \geq 0 \\ 0 & , x \leq 0\end{cases}
$$

(2) Nonlinear transformation function

Nonlinear transform functions commonly used for sigmoid function curve of unipolar which is referred to as $S$ type function. The $S$ type function and its derivative are continuous. So the data processing is very convenient. The Unipolar S function is also called log sigmoid function. The function is shown as follows:

$$
f(x)=\frac{1}{1+e^{-x}}
$$

(3) Linear transformation function

The characteristics of the function are the neuronal input and output satisfies the linear relationship in a certain range.

The linear function is shown as follows

$$
f(x)=k x
$$

In order to ensure that model of BP network can training and learning the nonlinear relationship between the input and output, the hidden layer is selected the tangent $\mathrm{S}$ function.

\section{The Simulation and Conclusion}

We borrow and streamline their indexes by learning the paper [17]. We can get some message by selecting: After screening indicator we can get that technological innovation can be explained by three first level indicators--quantity of technological innovation talents inventory, quality of technological innovation talents and the structure of technological innovation talents. Wherein the number of technological innovation talents can be reflected by rate of resources, density of technological innovation talents and growth rate of technological innovation talents.

The quality of technological innovation talents can be reflected by the number of scientists and engineers accounted for the proportion of technical personnel. Structure of technological innovation talents can be illustrated by education index of technological innovation talents, age index of technological innovation talents and title index of technological innovation talents. Efficiency of technological innovation talents can be illustrated by per capita quantity of invention patents, per capita quantity of scientific papers and per capita technology market turnover. Development environment of technological innovation talents mainly focuses on economic environment and it can be explained by per capita GDP, the growth rate of GDP and the growth rate of PMI. Details are shown in Table1 as following: 


\section{Table 1. Evaluation Index System of the Technological Innovation Talents' Competitiveness}

\begin{tabular}{|c|c|c|c|c|}
\hline Target layer & Element layer & $\begin{array}{l}\text { First grade } \\
\text { indices }\end{array}$ & & Second grade indices \\
\hline \multirow{13}{*}{$\begin{array}{l}\text { evaluation } \\
\text { index system } \\
\text { of the } \\
\text { technological } \\
\text { innovation } \\
\text { talents' } \\
\text { competitiveness }\end{array}$} & \multirow{7}{*}{$\begin{array}{l}\text { The stock of } \\
\text { technological } \\
\text { innovation } \\
\text { talents }\end{array}$} & \multirow{3}{*}{$\begin{array}{l}\text { Structure of } \\
\text { technological } \\
\text { innovation } \\
\text { talents }\end{array}$} & $x_{1}$ & $\begin{array}{l}\text { Education index of } \\
\text { technological } \\
\text { innovation talents }\end{array}$ \\
\hline & & & $x_{2}$ & $\begin{array}{c}\text { Age index of } \\
\text { technological } \\
\text { innovation talents }\end{array}$ \\
\hline & & & $x_{3}$ & $\begin{array}{c}\text { Title index of } \\
\text { technological } \\
\text { innovation talents }\end{array}$ \\
\hline & & \multirow{3}{*}{$\begin{array}{l}\text { The number } \\
\text { of } \\
\text { technological } \\
\text { innovation } \\
\text { talents }\end{array}$} & $x_{4}$ & $\begin{array}{c}\text { Rate of technological } \\
\text { innovation talent resources }\end{array}$ \\
\hline & & & $x_{5}$ & $\begin{array}{c}\text { Density of } \\
\text { technological } \\
\text { innovation talents }\end{array}$ \\
\hline & & & $x_{6}$ & $\begin{array}{c}\text { Growth rate of } \\
\text { technological } \\
\text { innovation talents }\end{array}$ \\
\hline & & $\begin{array}{l}\text { The quality of } \\
\text { technological } \\
\text { innovation } \\
\text { talents }\end{array}$ & $x_{7}$ & $\begin{array}{c}\text { The number of scientists and } \\
\text { engineers accounted } \\
\text { for of technical personnel }\end{array}$ \\
\hline & \multirow{3}{*}{$\begin{array}{l}\text { Efficiency of } \\
\text { technological } \\
\text { innovation } \\
\text { talents }\end{array}$} & \multirow{3}{*}{$\begin{array}{l}\text { The benefit of } \\
\text { technological } \\
\text { innovation } \\
\text { talents }\end{array}$} & $X_{8}$ & $\begin{array}{l}\text { Per capita quantity } \\
\text { of invention patents }\end{array}$ \\
\hline & & & $x_{9}$ & $\begin{array}{l}\text { Per capita quantity } \\
\text { of scientific papers }\end{array}$ \\
\hline & & & $x_{10}$ & $\begin{array}{c}\text { Per capita technology } \\
\text { market turnover }\end{array}$ \\
\hline & \multirow{3}{*}{$\begin{array}{c}\text { Development } \\
\text { environment } \\
\text { of } \\
\text { technological } \\
\text { innovation } \\
\text { talents }\end{array}$} & \multirow{3}{*}{$\begin{array}{l}\text { Economic } \\
\text { environment }\end{array}$} & $x_{11}$ & Per capita GDP \\
\hline & & & $X_{12}$ & The growth rate of local GDP \\
\hline & & & $X_{13}$ & The growth rate of PMI \\
\hline
\end{tabular}

Connotation of the indexes can be explained as following:

$\mathrm{X}_{1}$ : Education index of technological innovation talent: It refers to the product of the proportion of technological innovation at all levels of education and their weight. It reflects the education constitute of technological innovation.

Calculation method: Make the technological innovation talents of undergraduate education 1 and technological innovation talents of graduate education, college, tertiary qualifications are defined as 1.2, 0.8, 0.6. Technological innovation education index is equal to all academic levels of technological innovation and its right proportion number of the product. Education index of technological innovation talent is the product of the proportion of technological innovation at all levels of education and their weight. 
$\mathrm{X}_{2}$ : Age index of technological innovation talents: It refers to the production of the proportion of technological innovation talents of all ages and their weight. It reflects the age composition of regional technological innovation talents.

Calculation method: Define the technological innovation talents under 35 as 1 and talents between 36 and 45 as 0.8 . Technological innovation talents between 46 and 55 are defined as 0.6 . Those who are over 56 are defined as 0.4 .

$\mathrm{X}_{3}$ : Title index of technological innovation talents: It refers to the product of proportion of technological innovation talents with different titles and their weight during the report period.

Calculation method: Define senior titles as 1, intermediate titles as 0.3 and primary titles as 0.1 .

$\mathrm{X}_{4}$ : Rate of technological innovation talent resources: It refers to the proportion that technological innovation talent accounted for of all employees.

Calculation method: Rate of technological innovation talent resources $=$ (the total of technological innovation talents / the total of practitioners)* $100 \%$

$\mathrm{X}_{5}$ : Density of technological innovation talents: It refers to regional technological innovation talents accounted for of human resources.

Calculation method: Density of technological innovation talents $=$ (the total of technological innovation talents / the total of people) $* 100 \%$

$\mathrm{X}_{6}$ : Growth rate of technological innovation talents: It refers to the increment of technological innovation talents accounted for of all the technological innovation talents during the base period. It reflects the incremental level of technological innovation talents.

Calculation method: Growth rate of technological innovation talents $=$ (the increment of technological innovation talents / the number of technological innovation talents during the base period) $* 100 \%$

$\mathrm{X}_{7}$ : The number of scientists and engineers accounted for of technical personnel: It refers to scientists and engineers accounted for of all technological personnel.

Calculation method: The number of scientists and engineers accounted for of technical personnel $=($ the number of scientists and engineers / the number of technical personnel) $* 100 \%$

$\mathrm{X}_{8}$ : Per capita quantity of invention patents: It refers to the number of invention patents to the number of technological innovation talents ratio. It reflects the invention and creation ability of technological innovation talents in new technology, new products and new process.

Calculation method: Per capita quantity of invention patents= (the number of invention patents / the number of technological innovation talents)*100\%

$\mathrm{X}_{9}$ : Per capita quantity of scientific papers: It is the number of scientific papers that main foreign retrieval tools include to the number of technological innovation talents. It reflects the competence theory research and basic research ability of technological innovation talents.

Calculation method: Per capita quantity of scientific papers $=($ the number of scientific papers that main foreign retrieval tools include / the number of technological innovation talents) $* 100 \%$

$\mathrm{X}_{10}$ : Per capita technology market turnover: It refers to technology market turnover to the number of technological innovation talents ratio. It reflects the transformation and diffusion ability of technological innovation talents' innovation benefits.

Calculation method: Per capita technology market turnover= (technology market turnover / the number of technological innovation talents) $* 100 \%$

$\mathrm{X}_{11}$ : Per capita GDP: It is the ratio of GDP to total population during the report period and it reflects the level of economic development.

Calculation method: Per capita GDP $=(\mathrm{GDP} /$ total population $) * 100 \%$

$\mathrm{X}_{12}$ : The growth rate of local GDP: It is the increment of GDP to GDP of base period ratio. It represents the ability of the sustainable development of the economy. 
Calculation method: The growth rate of local GDP= (current GDP - GDP of the base period) / GDP of the base period $* 100 \%$

$\mathrm{X}_{13}$ : The growth rate of PMI: It's the difference between current PMI and base period PMI to the base period PMI ratio. It also mirrors the ability of the sustainable development of the economy.

Calculation method: The growth rate of PMI= (current PMI - PMI of the base period) / PMI of the base period $* 100 \%$

We give a table of sample data after normalization about the technological innovation talents of the six provinces.

Table 2. The Training Data Table of BP Neural Network

\begin{tabular}{|c|c|c|c|c|c|c|}
\hline \multicolumn{2}{|r|}{ Index } & 1 & 2 & 3 & 4 & 5 \\
\hline$x_{1}$ & $\begin{array}{l}\text { Education index of } \\
\text { technological } \\
\text { innovation talents }\end{array}$ & 0.86 & 0.84 & 0.77 & 0.80 & 0.81 \\
\hline$x_{2}$ & $\begin{array}{c}\text { Age index of } \\
\text { technological } \\
\text { innovation talents }\end{array}$ & 0.65 & 0.66 & 0.62 & 0.54 & 0.56 \\
\hline$x_{3}$ & $\begin{array}{c}\text { Title index of } \\
\text { technological } \\
\text { innovation talents }\end{array}$ & 0.67 & 0.64 & 0.62 & 0.65 & 0.59 \\
\hline$x_{4}$ & $\begin{array}{c}\text { Rate of technological } \\
\text { innovation talent resources }\end{array}$ & 0.84 & 0.81 & 0.83 & 0.81 & 0.79 \\
\hline$x_{5}$ & $\begin{array}{c}\text { Density of } \\
\text { technological } \\
\text { innovation talents }\end{array}$ & 0.85 & 0.83 & 0.81 & 0.83 & 0.78 \\
\hline$x_{6}$ & $\begin{array}{c}\text { Growth rate of } \\
\text { technological } \\
\text { innovation talents }\end{array}$ & 0.76 & 0.72 & 0.70 & 0.70 & 0.68 \\
\hline$x_{7}$ & $\begin{array}{l}\text { The number of scientists } \\
\text { and engineers accounted } \\
\text { for of technical personnel }\end{array}$ & 0.81 & 0.83 & 0.81 & 0.78 & 0.80 \\
\hline$X_{8}$ & $\begin{array}{l}\text { Per capita quantity } \\
\text { of invention patents }\end{array}$ & 0.87 & 0.84 & 0.86 & 0.83 & 0.81 \\
\hline$x_{9}$ & $\begin{array}{l}\text { Per capita quantity } \\
\text { of scientific papers }\end{array}$ & 0.81 & 0.79 & 0.79 & 0.80 & 0.76 \\
\hline$X_{10}$ & $\begin{array}{l}\text { Per capita technology } \\
\text { market turnover }\end{array}$ & 0.83 & 0.80 & 0.82 & 0.79 & 077 \\
\hline$x_{11}$ & Per capita GDP & 0.66 & 0.68 & 0.65 & 0.63 & 0.60 \\
\hline$x_{12}$ & $\begin{array}{l}\text { The growth rate } \\
\text { of local GDP }\end{array}$ & 0.65 & 0.62 & 0.64 & 0.61 & 0.60 \\
\hline$X_{13}$ & The growth rate of PMI & 0.75 & 0.72 & 0.73 & 0.69 & 0.68 \\
\hline
\end{tabular}

In this paper, we use three-layer BP network structure to evaluate the development of technological innovation talents in the six central provinces. The selection of the number of neurons in hidden layer is a very complex issue. In this paper, we will figure out the most appropriate number of hidden layers according to the following golden theory in Table 2. 
The theoretical study shows that the increase in the numbers of hidden layer, and increase the number of hidden layer nodes can improve the precision of network training. Increasing the node number of neurons in hidden layer is easier to realize than increasing the numbers of hidden layer. Up to now for the determination of node number of neurons in the hidden layer is mainly through the error method and experience method. We use the method of Fibonacci method to determine the node number of BP network hidden layer nodes. According to the Fibonacci method, the number of input layer nodes is $k$, the number of output layer nodes is $l$ , and the hidden layer node number is $m$.

Where the $m \in[a, b]$, and it satisfies the following formula:

$$
a=(k+l) / 2 \leq m \leq(k+l)+10=b
$$

We use the Matlab to construct BP neural network in this article. The Tansig function is used as the neuron transfer function of BP network hidden layer, namely the tangent function of $S$ type. Because the target output value of BP network output layer which is 1, 2, 3, 4 and 5 , the use of pure linear function as the transfer function of output layer neurons. LM algorithm is used for the training samples that namely trainlm function. The training rate is set to 0.5 , the expected error is one in a million, and the largest network of training time is set to 1000 .

Step 1:

In this paper, $k=13$ is the input layer node of BP neural network, and $l=1$ is the output layer node. According to the formula 4, we can get $a=7$ and $b=24$. According to the Fibonacci method, we can get $g_{1}=16.441$ and $g_{2}=13.314 \cdot g_{1}$ is approximated by 16, and $g_{2}$ is approximated by 13 . We use the BP network to train the data of total sample and use the non training data to forecast. We can get the values of mean square error which is $E\left(g_{1}\right)$ and $E\left(g_{2}\right)$. Also we can get the comparative results of expected value and actual value. As shown in Figure 2 and Figure 3.

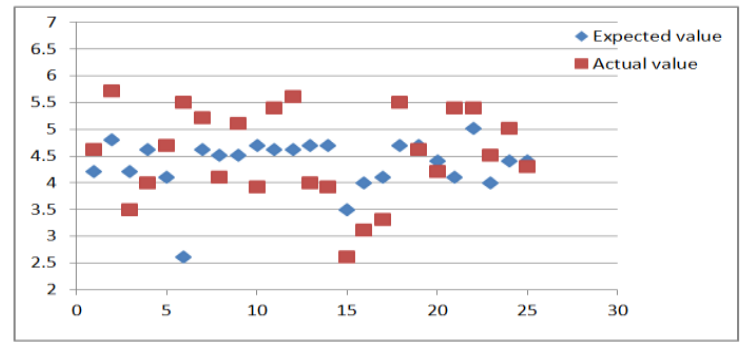

Figure 2. Output Value of BP Neural Network that the Node Number is 18 and the Mean Square Error is $\mathbf{0 . 8 1 2 2 7}$

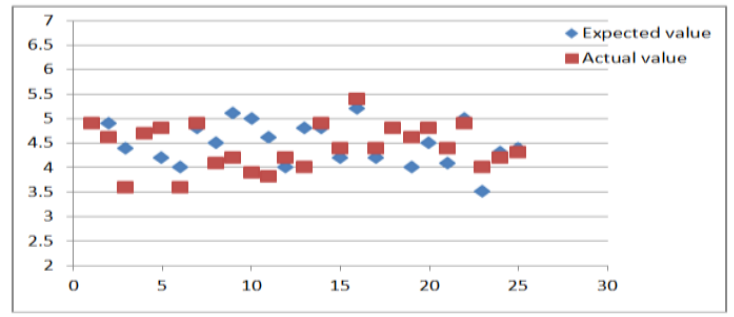

Figure 3. Output Value of BP Neural Network that the Node Number is 13 and the Mean Square Error is $\mathbf{0 . 2 5 8 3 1}$ 
We can see from the figure of results of training, the number of hidden nodes for 18 that the mean square error is 0.812 , and the number of hidden nodes for 13 that the mean square error is 0.258 . That is to say the $E\left(g_{1}\right)>E\left(g_{2}\right)$.According to the principle of the Fibonacci method, we keep the $[7,18]$, and give up $[18,24]$.

\section{Step 2:}

We use the Fibonacci method in $[7,18]$.

According to the Fibonacci method, we can get $g_{3}=13.133$ and $g_{4}=10.251 \cdot g_{3}$ is approximated by 13 , and $g_{4}$ is approximated by 10 . We use the BP network to train the data of total sample, and use the non training data to forecast. We can get the values of mean square error which is $E\left(g_{3}\right)$ and $E\left(g_{4}\right)$. Also we can get the comparative results of expected value and actual value. As shown in Figure 4 and Figure 5.

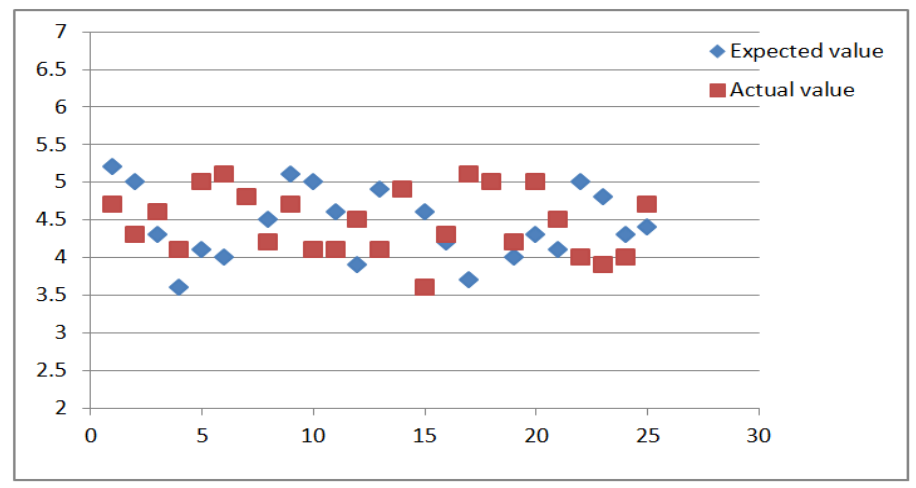

Figure 4. Output Value of BP Neural Network that the Node Number is 14 and the Mean Square Error is 0.26686

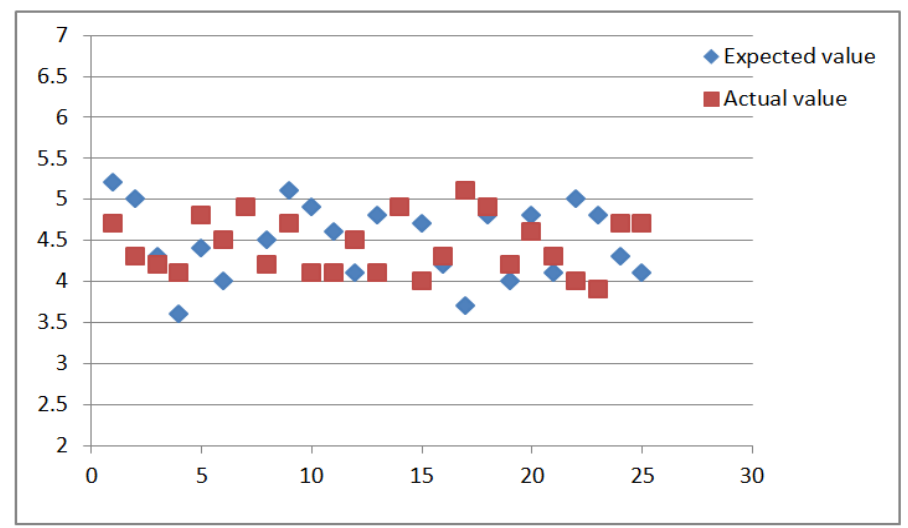

Figure 5. Output Value of BP Neural Network that the Node Number is 11 and the Mean Square Error is 0.19235

We can see from the figure of results of training, the number of hidden nodes for 14 that the mean square error is 0.266 , and the number of hidden nodes for 11 that the mean square error is 0.192 . That is to say the $E\left(g_{3}\right)<E\left(g_{4}\right)$.According to the principle of the Fibonacci method, we keep the $[7,14]$, and give up $[14,18]$. 
Step 3:

We use the Fibonacci method in $[7,14]$.

According to the Fibonacci method, we can get $g_{5}=11.124$ and $g_{6}=9.19 \cdot g_{5}$ is approximated by 11 , and $g_{6}$ is approximated by 9 . We use the BP network to train the data of total sample, and use the non training data to forecast. We can get the values of mean square error which is $E\left(g_{5}\right)$ and $E\left(g_{6}\right)$. Also we can get the comparative results of expected value and actual value. As shown in Figure 5 and Figure 6.

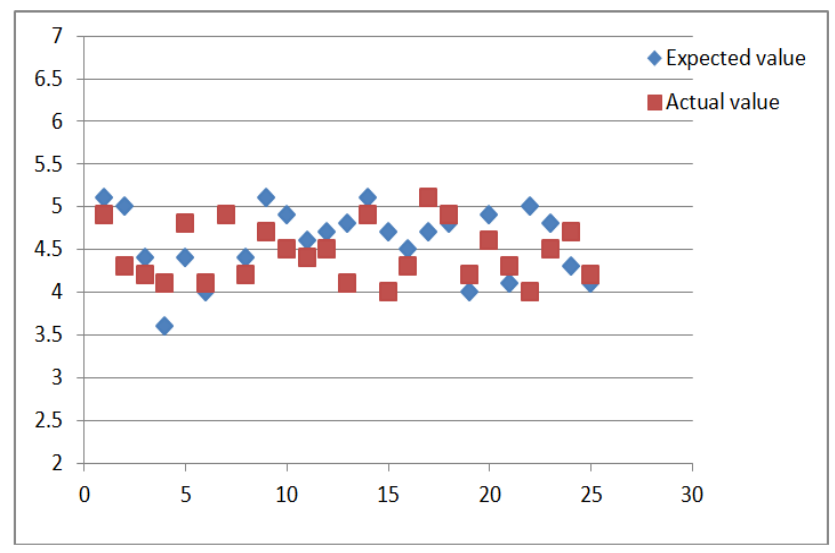

Figure 6. Output Value of BP Neural Network that the Node Number is 10 and the Mean Square Error is 0.06614

Step 4:

We use the Fibonacci method in [7,11].

According to the Fibonacci method, we can get $g_{7}=9.26$ and $g_{8}=8.94 \cdot g_{7}$ and $g_{8}$ is approximated by 9 . We can get the comparative results of expected value and actual value. As shown in Figure 7.

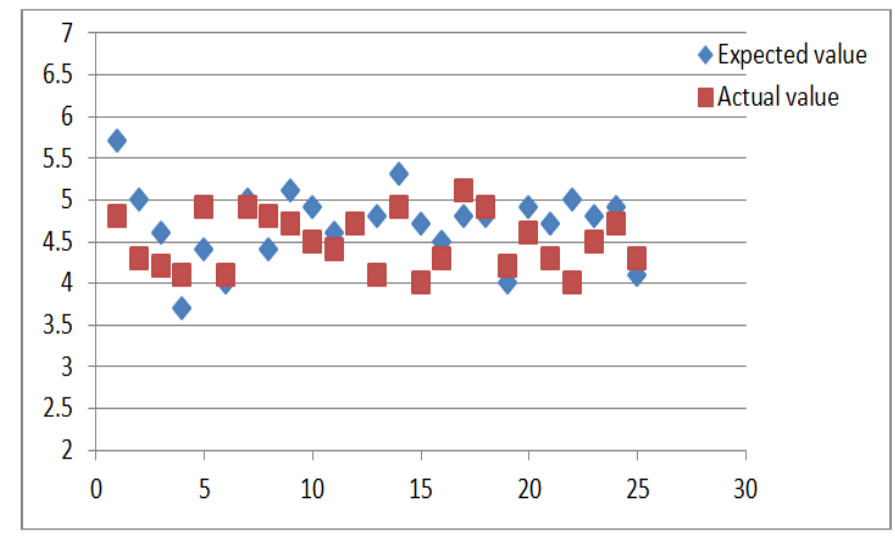

Figure 7. Output Value of BP Neural Network that the Node Number is 9 and the Mean Square Error is $\mathbf{0 . 1 0 3 3 1}$

Above all, when the BP network hidden layer node is 10, the mean square error reaches the minimum. 
Based on ensured hidden layers, we have trained and learnt neural network for 13651 times. Then the error convergences and the result is shown below:

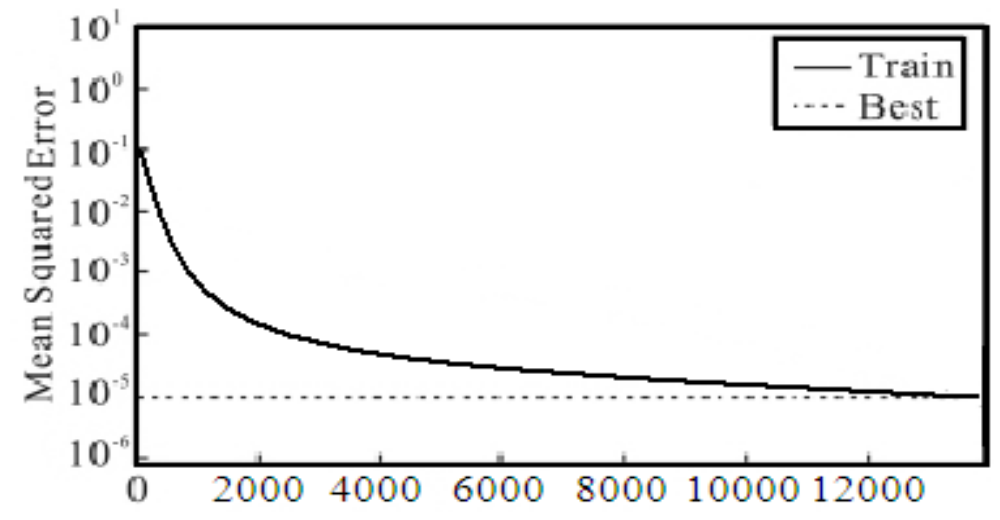

Figure 8. Schematic Diagram of Error Convergence of BP Neural Network

Now we have finished training the network model and it has got a certain training accuracy (see Table 2). The evaluation model of technological innovation talents of the six central provinces has been established based on BP neural network and it can be tested for use.

After the calculation of Table 2, technological innovation talent evaluation score chart is given as follows:

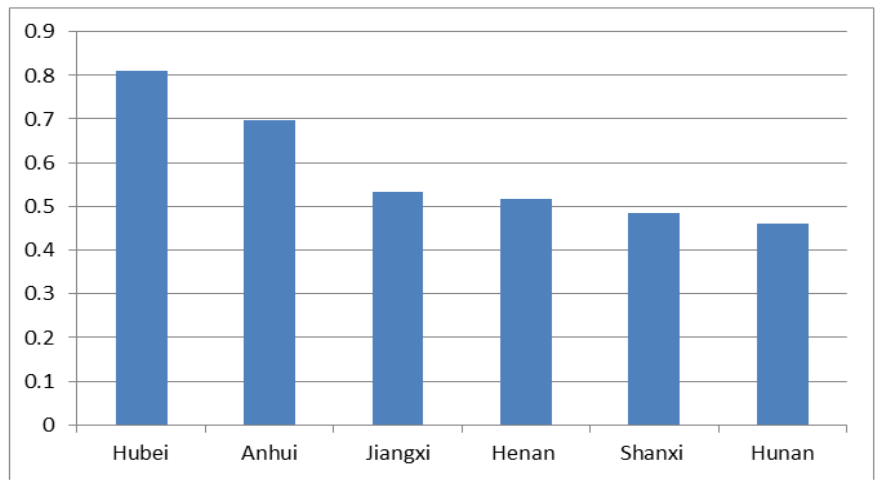

\section{Figure 9. Evaluation Score of Technological Innovative Talents' Competitiveness of the Six Provinces in Mid-China}

According to the result, we can get that the order of the merits of regional technological innovation talents' competitiveness is: Hubei, Anhui, Jiangxi, Henan, Shanxi, Hunan. Hubei has the strongest technological innovation talents' competitiveness among the six central provinces. Its technological capital investment and technological achievements output are both much more than other provinces. It can even be compared with some developed eastern coastal provinces. Competitiveness of technological innovation talents of Anhui is next to that of Hubei and it is much higher than that of other four provinces. Some indexes of Anhui are even higher than Hubei mainly because the number of scientific research institutions and patent applications of Anhui is high and better than the national average. The competitiveness level of other four provinces is similar. Although their innovation development is better than a few years ago, they still need more time and more input. We can believe than the midlands 
will make great progress in the future and have more technological innovation talents contribute to the development of science and economy.

\section{References}

[1] D. Gursoya and T. A. Maie, "Generational differences: An examination of work values and generational gaps in the hospitality workforce [J]", International Journal of Hospitality Management, vol. 27, no. 3, (2008), pp. 448-458.

[2] R. S. Akhta, D. Z. Ding and Gloria, "A retrospective and prospective analysis of HRM research in Chinese firm Implications and directions for future study[J]”, Human Resource Management, vol. 47, (2008), pp. 1532

[3] K. R. Browne, "Evolves sex differences and occupational segregation [J]", Journal of Organizational Behavior, vol. 27, (2006), pp. 143-162.

[4] J. Agell, K. Lommerud and Efik, "Minimum wages and the incentives for skill formation [J]", Journal of Public Economics, vol. 64, (1997), pp. 25-40.

[5] J. D. Shin and D. Menicucci, "Money, fame and the allocation of talent: Brain drain and the institution of science [J]", Journal of Economic Behavior \& Organization, vol. 66, (2008), pp. 558-581.

[6] D. Acemoglu, "Reward structures and the allocation of talent [J]", European Economic Review, vol. 39, (1995), pp. 17-33.

[7] G. Werther, "Building an "Analysis Age" for Competitive Intelligence in the Twenty-First Century [J]", Competitive Intelligence Review, vol. 12, no. 1, (2002), pp. 41-47.

[8] S. Hung, "Development and innovation in the IT industry's of India and China [J]", Technology inSociety, vol. 1, (2008), pp. 2-17.

[9] J. M. Hiltrop, "Creating HR capability in high performance organizations [J]", Strategic Change, vol. 14, (2005), pp. 121-131

[10] C. Chen, Jen and W. Huang Jing, "Strategic human resource practices and innovation performance-The mediating role of knowledge management capacity [J]", Journal of Business Research, (2008), vol. 2, no. 5, pp. 33-45.

[11] T. G. Gardner, "In the trenches at the talent wars: Competitive interaction for scarce human resources [J]", Human Resource Management, vol. 41, no. 2, (2002), pp. 225-237.

[12] A. M. Marino, "Delegation versus an approval process and the demand for talent [J]", International Journal of Industrial Organization, vol. 24, (2006), pp. 487-503.

[13] S. Akhtar, D. Ding and G. Gloria, "Strategic HRM Practices and Their Impact on Company Performance in Chinese Enterprises [J]", Human Resource Management, vol. 47, no. 1, (2008), pp. 15-32.

[14] M. Harvey, "Focusing the International Personnel Performance Appraisal Process [J]", Human Resource Development Quarterly, vol. 8, no. 1, (1997), pp. 41-62.

[15] M. G. Harvey and R. G. Richey, "Global Supply Chain Management [J]", Journal of International Management, vol. 7, (2001), pp. 105-128.

[16] K. K. Kirby, "Recruiting Top Talent: Another Way to Contribute [J]", Nurse Leader, vol. 2, (2008), pp. 34-37.

[17] W.-M. Chen, "Research on the Evaluation and Forecast for Regional Competitiveness of Technological Innovation Talents [D]”, Nanjing University, (2011).

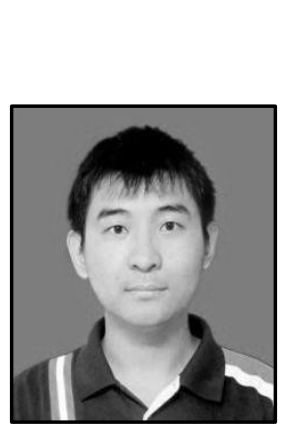

\section{Author}

Huaping Zhang, Male, was born on May 7th, 1980, from Dongying City, Shandong Province, China. He received his Bachelor's degree in Trade Economics (2002) and Master's degree in Management Science and Engineering (2008) from North China University of Water Resources and Electric Power and Doctor's degree in National Economics (2011) from Henan University. Now he is full associate professor of business management in Management \& Economics School of North China University of Water Resources and Electric Power. His current research interests include business strategic management, cost management accounting, together with technological economic management. 